\title{
Comunicação/Communication
}

\section{Atividade larvicida do extrato bruto enzimático do fungo Duddingtoniaflagras sobre larvas de primeiro estádio de Angiostrongylus vasorum}

\author{
Larvicidal activity of a crude enzyme extract of the fungus Duddingtonia flagrans on first-stage \\ larvae of Angiostrongylus vasorum
}

\begin{abstract}
Fabio Ribeiro Braga ${ }^{1}$, Juliana Milani Araujo ${ }^{1}$, Alexandre de Oliveira Tavela ${ }^{1}$, Jackson Victor de Araújo ${ }^{1}$, Filippe Elias de Freitas Soares ${ }^{2}$, Hugo Leonardo André Geniêr ${ }^{2}$, Walter dos Santos Lima ${ }^{3}$, Lanuze Rose Mozzer ${ }^{3}$ e José Humberto de Queiroz ${ }^{2}$
\end{abstract}

\begin{abstract}
RESUMO
Introdução: Angiostrongylus vasorum é um nematóide que parasita cães domésticos e eventualmente o homem. Métodos: $O$ objetivo deste trabalho foi observar a atividade predatória in vitro do extrato bruto enzimático do fungo Duddingtonia flagrans sobre larvas de primeiro estádio A. vasorum em condições laboratoriais no meio ágar-água 2\%. Resultados: Ao final do experimento, os percentuais de redução das $\mathrm{L}_{1}$ de $A$. vasorum observados foram de: $53,5 \%(24 \mathrm{~h})$ e $71,3 \%$ (48h) Conclusões: O extrato bruto enzimático do fungo D. flagrans destruiu in vitro as $\mathrm{L}_{1}$, podendo ser utilizado como controle biológico desse nematóide.
\end{abstract}

Palavras-chaves: Fungos nematófagos. Angiostrongylus vasorum. Duddingtonia flagrans.

\begin{abstract}
Introduction: Angiostrongylus vasorum is a nematode parasite of domestic dogs and potentially of humans. Methods: This study aimed to observe the predatory activity in vitro of a crude enzyme extract of the fungus Duddingtonia flagrans on first-stage larvae of $A$. vasorum in laboratory conditions on 2\% water-agar. Results: At the end of the experiment, the percentage reductions observed for $A$. vasorum $\mathrm{L}_{1}$ were $53.5 \%(24 \mathrm{~h})$ and $71.3 \%(48 \mathrm{~h})$. Conclusions: Crude enzyme extract of the fungus D. flagrans destroyed the $\mathrm{L}_{1}$ in vitro and can be used as a biological control for this nematode. Keywords: Nematophagous fungi. Angiostrongylus vasorum. Duddingtonia flagrans.
\end{abstract}

Angiostrongylus vasorum (Baillet, 1866) Kamensky, 1905, é um nematóide protostrongilídeo, de distribuição cosmopolita. O parasita adulto pode ser encontrado no ventrículo direito, artérias pulmonares e suas ramificações, o que pode causar consequências graves para o hospedeiro definitivo (cães domésticos e canídeos silvestres) e eventualmente o homem. Embora não existam dados sobre a prevalência do A. vasorum no Brasil, trabalhos têm demonstrado sua ocorrência em diferentes estados ${ }^{1}$. O ciclo biológico do $A$. vasorum é do tipo heteroxeno, diversas espécies de moluscos aquáticos e terrestres são os hospedeiros intermediários. Nas arteríolas

1. Departamento de Veterinária, Universidade Federal de Viçosa, Viçosa, MG. 2. Departamento de Bioquímica e Biologia Molecular, Universidade Federal de Viçosa, Viçosa, MG. 3. Departamento de Parasitologia Animal, Universidade Federal de Minas Grais, Belo Horizonte, MG.

Endereço para correspondência: Dr. Fabio Ribeiro Braga. Depto de Veterinária/UFV. Av. Ph Rolfes s/n, 36570-000 Viçosa, MG.

Tel: $55313899-1458$

e-mail: fabioribeirobraga@hotmail.com

Recebido para publicação em 13/05/2010

Aceito em 05/01/2011 pulmonares do hospedeiro definitivo, ocorre o embrionamento dos ovos até o desenvolvimento das larvas de primeiro estádio $\left(\mathrm{L}_{1}\right)$, que eclodem e passam ativamente para os alvéolos, bronquíolos e brônquios. Estas $\mathrm{L}_{1}$ migram para a traquéia e são expelidas junto a secreções pulmonares ou são deglutidas e eliminadas junto com as fezes ${ }^{1,2}$. As $L_{1}$ permanecem no bolo fecal, ou podem alcançar coleções de água. Moluscos terrestres ou aquáticos infectam-se ingerindo $\mathrm{L}_{1}$ via trato digestivo, ou pela penetração delas pelas partes moles do molusco. Após os cães ingerirem as larvas infectantes, estas penetram na parede do trato digestivo migram até os linfonodos mesentérios, onde ocorre a muda de $\mathrm{L}_{3}$ para larva de quarto estádio $\left(\mathrm{L}_{4}\right)$, por volta do terceiro dia de infecção e a muda de $\mathrm{L}_{4}$ para larva de quinto estádio $\left(\mathrm{L}_{5}\right)$, em torno do quinto dia de infecção ${ }^{3}$. O conhecimento do ciclo vital de Angiostrongylus, apesar de incompleto, mostra uma complexidade de situações nas quais o homem pode aparece como hospedeiro eventual. Nos animais, os sintomas clínicos mais frequentes são tosse, dispnéia, intolerância ao exercício, perda de peso, sinais neurológicos, deficiências cardíacas e morte $\mathrm{e}^{4,5}$.

A maioria dos anti-helmínticos não age bem sobre A. vasorum no hospedeiro definitivo, portanto, medidas alternativas que possam ser empregadas no combate à disseminação ambiental deste parasito e de suas formas infectantes são importantes, como o uso de antagonistas naturais de helmintos. Fungos predadores são certamente os grupos mais estudados e que apresentam o maior potencial de biocontrole de hemintos ${ }^{6}$. A espécie Duddingtonia flagrans produz clamidósporos e pode produzir uma série de enzimas, dentre essas as proteases. Além disso, tem sido utilizado com sucesso no combate as formas infectantes de nematóides potencialmente zoonóticos ${ }^{7,8}$ e, o desenvolvimento de formulações fúngicas para uso no controle biológico é um dos principais passos para a produção comercial destes microorganismos ${ }^{9}$.

O objetivo deste trabalho foi observar a atividade predatória in vitro do extrato bruto enzimático do fungo $D$. flagrans sobre larvas de primeiro estádio de A. vasorum.

Foi utilizado um isolado de D. flagrans (AC001), oriundo de solo brasileiro, do município de Viçosa na zona da mata de Minas Gerais, (latitude $20^{\circ} 45^{\prime} 20^{\prime} \mathrm{S}$, longitude $42^{\circ} 52^{\prime} 40^{\prime \prime} \mathrm{W}$, a $649 \mathrm{~m}$ do nível do mar). O fungo foi mantido em tubos de ensaio a $4^{\circ} \mathrm{C}$ contendo cornmeal-ágar 2\% (CMA 2\%), no escuro por 10 dias. Micélios fúngicos foram obtidos através da transferência de discos de cultura (cerca de $5 \mathrm{~mm}$ de diâmetro) dos isolados fúngicos mantidos em corn meal 
ágar 2\% (CMA 2\%) para frascos erlenmeyers $(250 \mathrm{~mL})$ contendo $50 \mathrm{~mL}$ de meio líquido de acordo com a metodologia descrita por Meyers e Wiebe ${ }^{7}$. O meio líquido foi composto por: glicose (10g/l), caseína $(18,409 \mathrm{~g} / \mathrm{l}), \mathrm{K}_{2} \mathrm{HPO}_{4}(5,0 \mathrm{~g} / \mathrm{l}) \mathrm{MgSO}_{4}(0,10 \mathrm{~g} / \mathrm{l}), \mathrm{ZnSO}_{4}$ $(0,0050 \mathrm{~g} / 1) ; \mathrm{FeSO}_{4}(0,001 \mathrm{~g} / 1)$ e $\mathrm{CuSO}_{4}(0,50 \mathrm{mg} / \mathrm{l})$. Os frascos erlenmeyers contendo o inóculo fúngico cresceram em aparelho Shaker sob agitação de $120 \mathrm{rpm}$ e pH 9,0. Depois de seis dias o sobrenadante foi coletado e filtrado, em papel filtro Whatman n. 1 a $4^{\circ} \mathrm{C}$.

A cepa utilizada de $A$. vasorum foi originalmente isolada das fezes de dois cães naturalmente infectados, prodecentes do município de Caratinga, $\mathrm{MG}^{10}$. Esta cepa vem sendo mantida por passagens sucessivas em cães.

Fezes de cães infectados foram colhidas e colocadas em aparelho de Baermann modificado para a recuperação das $L_{1}{ }^{11}$. As fezes permaneceram no aparelho por $12 \mathrm{~h}$, e o sedimento foi centrifugado a $200 \mathrm{Xg}$, por $2 \mathrm{~min}$. O sobrenadante foi desprezado e o sedimento contendo as $\mathrm{L}_{1}$ de $A$. vasorum foi ressuspenso em $5 \mathrm{~mL}$ de salina $0,8 \%$ e alíquotas de $10 \mu \mathrm{L}$ foram contadas com auxílio de estereomicroscópio no aumento de $25 \mathrm{x}$ e estimou-se a quantidade total de larvas recuperadas.

Dois grupos foram formados em tubos eppendorf de $1,5 \mathrm{~mL}$ estéreis, um grupo tratado e um grupo controle nos horários de 24 e $48 \mathrm{~h}$, sendo feitas seis repetições para cada grupo em cada horário estudado. No grupo tratado, $50 \mathrm{~L}_{1}(20 \mu \mathrm{l})$ de $A$. vasorum foram vertidas em tubos eppendorf de $1,5 \mathrm{~mL}$ estéreis contendo $150 \mu \mathrm{l}$ de extrato bruto enzimático de $D$. flagrans (AC001). O grupo controle continha $50 \mathrm{~L}_{1}(20 \mu \mathrm{l})$ de $A$. vasorum em $150 \mu \mathrm{l}$ de extrato enzimático bruto fervido por 10min no tubo eppendorf de 1,5ml estéril. Os tubos foram incubados a $25^{\circ} \mathrm{C}$, no escuro, por 24-48h. Após incubação, foi contado o número total das $\mathrm{L}_{1}$ de $A$. vasorum presentes em cada tubo - tratamento de acordo com a metodologia descrita por Niu cols ${ }^{12}$.

Os dados obtidos nesse ensaio foram analisados estatisticamente pela análise de variância em níveis em níveis de significância de 1 e $5 \%$ de probabilidade. A eficiência de predação das $\mathrm{L}_{1}$ em relação ao controle em cada tempo ( 24 e $48 \mathrm{~h}$ ) foi avaliada pelo teste de Tukey ao nível de $1 \%$ de probabilidade.

O percentual de redução da média de larvas foi calculado de acordo com a seguinte equação:

$\%$ redução $=($ média de larvas do controle - médias de larvas do tratamento $) \times 100$ média de larvas do controle

No intervalo de $24 \mathrm{~h}$, o extrato bruto enzimático de D. flagrans (AC001) apresentou um percentual de redução de 53,5\% sobre as $\mathrm{L}_{1}$ de $A$. vasorum. Para o intervalo de 48 horas, o extrato bruto enzimático de AC001 foi capaz de destruir $71,3 \%$ das $\mathrm{L}_{1}$. Por outro lado, foi notada diferença $(\mathrm{p}<0,05)$ no número de larvas destruídas presentes nos grupos tratados em relação às larvas presentes nos grupos controle, nos dois intervalos de tempo estudados. A comprovação da atividade larvicida do extrato enzimático de AC001 sobre as $\mathrm{L}_{1}$ de $A$. vasorum está demonstrada na Figura 1 (A-B).

$A$. vasorum, além de sua importância médico-veterinária, como parasita cardiopulmonar de cães domésticos e canídeos silvestres, requer atenção especial e investigação, uma vez que pode infectar o homem ${ }^{13}$. Em trabalho recente, Braga cols ${ }^{8}$ demonstraram que AC001 crescido meio de cultura sólido (AA 2\%) em placas de Petri destruiu $80,3 \%$ das $\mathrm{L}_{1}$ de $A$. vasorum ao final de sete dias. Comparando

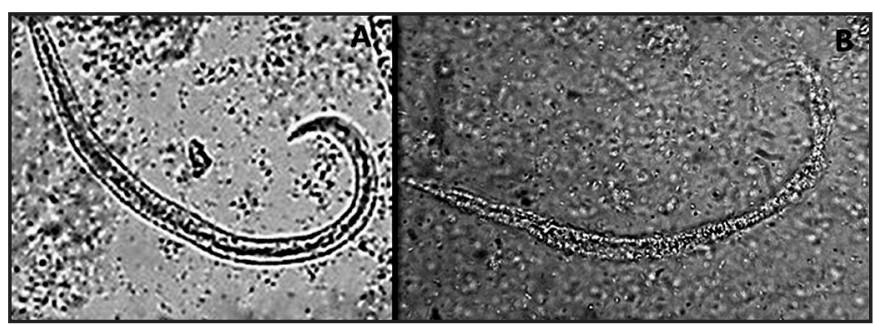

FIGURA 1 (A-B) - Larva $\left(\mathrm{L}_{1}\right)$ de Angiostrongylus vasorum tratada com extrato bruto enzimático de Duddingtonia flagrans no período de 24h (grupo tratado; A) e 48h (grupo tratado; B).

sua atividade predatória no presente trabalho, nota-se que a utilização do seu extrato bruto enzimático é promissora, uma vez que, a destruição das larvas ocorreu após $24 \mathrm{~h}(53,5 \%)$ e se manteve até o final do experimento com atividade predatória de $71,3 \%$ (48h). Este é o primeiro relato da atividade predatória de extrato bruto enzimático obtido a partir de um fungo nematófago, D. flagrans, o que poderá contribuir no futuro como uma ferramenta para novas pesquisas no combate as formas infectantes de nematóides. Na Figura 1 (B), pode-se observar a hidrólise da cutícula pela ação enzimática do extrato, o que permitiu que o mesmo também atuasse no interior do nematóide, causando a sua destruição.

Barçante ${ }^{4}$ demonstrou que a infecção de cães com $\mathrm{L}_{3}$ de $A$. vasorum pode ocorrer, independente da ingestão do hospedeiro intermediário e que cães podem se infectar ingerindo alimentos ou bebendo água onde tenham moluscos infectados. Além disso, pelo fato das larvas estarem livres no ambiente, abre-se a possibilidade de infecção humana, uma vez que outros parasitos do gênero Angiostrongylus são comprovadamente zoonóticos ${ }^{14,15}$. Nesse contexto, sugere-se a aplicabilidade dos fungos nematófagos, destacando-se o isolado AC001 da espécie D. flagrans.

Os resultados obtidos no presente trabalho confirmam trabalhos anteriores da eficiência de fungos nematófagos no controle de larvas de nematóides potencialmente zoonóticas.

\section{CONFLITO DE INTERESSE}

Os autores declaram não haver nenhum tipo de conflito de interesse no desenvolvimento do estudo.

\section{SUPORTE FINANCEIRO}

Coordenação de Aperfeiçoamento de Pessoal de Nível Superior (CAPES), Fundação de Amparo à Pesquisa de Minas Gerais (FAPEMIG) e Conselho Nacional de Desenvolvimento Científico e Tecnológico (CNPq).

\section{REFERÊNCIAS}

1. Patteson MW, Gibbs C, Wotton PR, Day MJ. Angiostrongylus vasorum infection in seven dogs. Vet Record 1993; 4:565-570.

2. Cury MC, Guimarães MP, Lima WS, Caldeira MCM, Couto TR, Murta K, et al. Biochemical serum profiles in dogs experimentally infected with Angiostrongylus vasorum (Baillet, 1866). Vet Parasitol 2002; 128:121-127.

3. Barçante TA. Aspectos do desenvolvimento de Angiostrongylus vasorum (Baillet, 1866) Kamensky, 1905 em Biomphalaria glabrata (Say, 1818). [Tese]. [Belo Horizonte]: Universidade Federal de Minas Gerais; 2006. 179p. 
4. Oliveira-Jr SD, Barçante JMP, Barçante TA, Dias SRC, Lima WS. Larval output of infected and re-infected dogs with Angiostrongylus vasorum (Baillet, 1866) Kamensky, 1905. Vet Parasitol 2004; 141:101-106.

5. Saeed I, Maddox-Hyttel C, Monrad J, Kapel CMO. Helminths of red fox (Vulpes vulpes) in Denmark. Vet Parasitol 2006; 139:168-179.

6. Nordbring-Hertz B, Jansson HB, Tunlid A. Nematophagous fungi In: Encyclopedia of Life Sciences. Basingstoke: Macmillan Publishers; 2002. p. 1-10.

7. Meyer WJ, Wiebe MG. Enzyme production by the nematode-trapping fungus, Duddingtonia flagrans. Biotechnol Letters 2003; 25:791-795.

8. Braga FR, Carvalho RO, AraujoJM, Silva AR, AraújoJV, Lima WS, et al. Predatory activity of the fungi Duddingtonia flagrans, Monacrosporium thaumasium, Monacrosporium sinense and Arthrobotrys robusta on Angiostrongylus vasorum first-stage larvae. J Helminthol 2009; 83:303-308.

9. Araújo JV, Mota MA, Campos AK. Controle biológico de helmintos parasitos de animais por fungos nematófagos. Rev Bras Parasitol Vet 2004; 13:165-170.

10. Lima WS, Costa HMA, Guimarães MP, Leite ACR. Angiostrongylus vasorum (Baillet, 1866) Nematoda: Prothostrongylidae em cães de Minas Gerais, Brasil. Mem Inst Oswaldo Cruz 1985; 80:233-235.

11. Barçante JMP, Barçante TA, Dias SRC, Vieira LQ, Lima WS, Negrão-Corrêa D A method to obtain axenic Angiostrongylus vasorum first-stage larvae from dog feces. Parasitol Res 2003; 89:89-93.

12. Niu Q, Huang X, Tian B,Yang J, Liu J, Zhang L, et al. Bacillus sp. B16 kills nematodes with a serine protease identified as a pathogenic factor. Appl Microbiol Biotechnol 2003; 69:722-730.

13. Eckert J, Lämmler G. Angiostrongylose bei Mensch und Tier. Parasitol Res $1972 ; 39: 303-322$

14. Rambo PR, Agostini AA, Graeff-Teixeira C. Abdominal Angiostrongylosis in Southern Brazil - Prevalence and Parasitic Burden in Mollusc Intermediate hosts from eighteen endemic foci. Mem Inst Oswaldo Cruz 1997; 92:9-14.

15. Prociv P, Spratt DM, Carlisle MS. Neuro-angiostrongyliasis: unresolved issues. Int J Parasitol 2000; 30:1295-1303. 